Abstracta Iranica Abstracta Iranica

Revue bibliographique pour le domaine irano-aryen

Volume 40-41 | 2019

Comptes rendus des publications de 2017-2018

\title{
Alexandre Kazerouni. Le miroir des cheikhs. Musée et politique dans les principautés du Golfe persique
}

Alice Bombardier

\section{OpenEdition}

1 Journals

Édition électronique

URL : http://journals.openedition.org/abstractairanica/48924

DOI : 10.4000 /abstractairanica.48924

ISBN : 1961-960X

ISSN : $1961-960 X$

Éditeur :

CNRS (UMR 7528 Mondes iraniens et indiens), Éditions de l'IFRI

Référence électronique

Alice Bombardier, "Alexandre Kazerouni. Le miroir des cheikhs. Musée et politique dans les principautés du Golfe persique », Abstracta Iranica [En ligne], Volume 40-41 | 2019, document 1, mis en ligne le 30 octobre 2019, consulté le 24 avril 2021. URL : http://journals.openedition.org/abstractairanica/48924 ; DOI : https://doi.org/10.4000/abstractairanica.48924

Ce document a été généré automatiquement le 24 avril 2021.

Tous droits réservés 


\title{
Alexandre Kazerouni. Le miroir des cheikhs. Musée et politique dans les principautés du Golfe persique
}

\author{
Alice Bombardier
}

\section{RÉFÉRENCE}

Alexandre Kazerouni. Le miroir des cheikhs. Musée et politique dans les principautés du Golfe persique. Paris : PUF, collection « Proche-Orient », 2017, 276 p.

1 Cet ouvrage reprend pour partie une thèse de doctorat soutenue en 2013 sous la direction de Gilles Kepel à l'Institut d'Etudes Politiques de Paris. Il répond à un projet d'étude du monde politique par le musée dans les principautés sises sur la rive orientale du Golfe arabo-persique. Il y est surtout question du Qatar et d'Abu Dhabi, même si d'autres émirats, ainsi que le sultanat d'Oman et le royaume de Bahreïn, sont mentionnés - l'émirat du Koweït ayant la particularité d'être cité régulièrement comme contre-modèle.

2 À la suite de recherches de terrain menées entre 2007 et 2013, l'A. procède à une analyse approfondie de plusieurs types de musées et de leurs maîtres d'œuvre, objets de réflexions emboitées qui tendent, somme toute, à éclairer le fonctionnement étatique des principautés. L'auteur fait ainsi du musée "un analyseur " des Etats (p. 245). Ses réflexions le conduisent à éclairer non seulement les rouages politiques mais aussi les relations contrastées des principautés sous la bannière d'une identité «golfienne» (p. 90).

3 Le plan de l'ouvrage mêle raisonnement chronologique et approche modélisante. La première partie, «La guerre du Golfe et les limites du musée classique »(I), est consacrée au "musée-racine » (musée-patrimoine ou musée-turath), nommé ainsi par l'auteur étant donné l'enracinement local ou national qui y est avant tout recherché. Un premier établissement muséal de ce type avait été fondé à Aden en 1931 sous l'ère 
britannique puis au Koweit en 1957 dans la lignée du développement éducatif moderne. Mais la matrice du musée-racine voit le jour en 1970 au Bahrein avant d'être érigée en modèle régional (Musée national d'Al-Ayn en 1971, Musée de Dubai en 1971, Musée national du Qatar en 1975...). Ces musées-racines, où les acteurs étrangers ne sont pas en reste, ont émergé des vestiges des «clubs» culturels, qui étaient auparavant dominés par les réseaux de marchands. Tandis que le chapitre 1 dans cette partie s'attache à retracer la genèse, l'évolution, les impasses, contenants et contenus de ce type de musée, le chapitre 2 change d'échelle, s'efforçant d'exposer les luttes d'influence et les dynamiques de l'ordre culturel régional dans les années 1990. Cette période correspond au temps de gestation de l'autre type de musée abordé ensuite. En effet, dans la deuxième partie, "Musée et dédoublement de l'Etat au Qatar et à Abu Dhabi » (II), l'auteur se concentre sur le «musée-miroir », qui représente localement une deuxième génération de musées mais clivée, non issue de la précédente. Ces «musées-miroirs »- terme issu du latin specula qui désigne en Europe au Moyen Âge les traités de bon gouvernement (ces ouvrages de conseils aux princes ou miroirs des princes ayant eu d'ailleurs leur équivalent dans le monde islamique [al-adab]) - ont pour rôle fondamental de consolider les familles régnantes sur la scène internationale. Le chapitre 3 présente le contexte d'émergence à partir des années 1990-2000 de ce deuxième type muséal, à l'appui principalement de deux exemples, le Musée d'art islamique de Doha et le Louvre Abu Dhabi, avant que le chapitre 4 n'induise son impact politique.

4 L'A. décortique minutieusement à l'échelle locale mais aussi macrorégionale, voire internationale, les rouages organisationnels tout en détaillant les jeux d'acteurs à l'origine de ces différentes politiques culturelles et muséales. Il n'est pas question des publics : l'intérêt est plutôt porté à ceux qui mettent en œuvre les espaces d'exposition, qu'ils soient artistes, marchands, collectionneurs, dirigeants politiques, membres des familles régnantes, prestataires de services étrangers et/ou fonctionnaires locaux. Son constat premier est celui d'un dédoublement de l'administration muséale : le muséemiroir est géré par des experts occidentaux qui procèdent à une "agencification » de l'Etat (p. 221) tandis que le musée-racine est aux mains des fonctionnaires locaux. Mais ces derniers sont écartés de la gestion de la nouvelle génération de musées et non formés pour en prendre la suite. Cette récente politique d'édification muséale sous l'égide des plus hautes sphères étatiques s'inscrit donc en rupture avec la société, laissée dormante. L'A. se démarque ainsi des chercheurs qui ont fait de la bureaucratie locale un outil au service des intérêts des familles princières (Jill Crystal, Christel Braae).

5 De ce premier constat découle la thèse innervant le cœur de l'ouvrage: la nonappropriation du musée-miroir par la société locale favorise l'autoritarisme des familles régnantes. Le musée-miroir, pourtant issu du modèle européen élaboré à l'époque moderne dans l'esprit du libéralisme, s'avère déconnecté de l'esprit des Lumières par l'autoritarisme qu'il promeut. Mais, si la configuration institutionnelle du musée-miroir renforce localement l'arbitraire politique, sa muséographie est, quant à elle, destinée au regard extérieur. Le musée-miroir est voué à « renvoyer au public [occidental] l'image de ses attentes vis-à-vis du monde musulman contemporain » (p.15). Le musée-miroir propose en la mythifiant une définition de l'islam dans le monde contemporain et fournit à l'Occident une représentation du prince musulman idéal. Mais cette mythification est aussi mystification car ces musées sont les creusets d'un double ou triple discours dont le but est avant tout de consolider les familles 
régnantes et leur idéologie. Ils en reflètent directement la vision, la ru'ya, dont la mise en scène très contrôlée tend en définitive selon l'auteur à donner de la visibilité et à renforcer une certaine définition du salafisme.

6 Il faut noter la place particulière accordée aux Iraniens au fil des pages. Leur rôle dans la construction identitaire arabe et golfienne a l'intérêt d'être circonstancié, de même que les dynamiques migratoires et les échanges culturels entre les deux rives du Golfe arabo-persique. Il s'avère que les liens avec l'Iran, de même que l'esclavage, sont deux « impensés", presque tabous, des musées arabes.

7 Si le plan de l'ouvrage - mélangeant les échelles et cloisonnant musée-racine et muséemiroir - pourrait manquer de fluidité, les exemples variés, les jeux d'acteurs, les nombreuses analyses ethnographiques et sémiologiques - par exemple des mannequins dans les dioramas ou à propos des cafetières (dalla) comme quintessence de l'artisanat bédouin - et discursives - tels les discours développementalistes passés au crible par l'auteur - ont l'avantage de rendre ces musées et leurs enjeux aisément perceptibles. En nous permettant d'accéder aussi bien officieusement qu'officiellement à l'ordre social, politique et culturel des principautés du Golfe, ce livre est précieux pour tous ceux qui souhaiteraient mieux comprendre leur fonctionnement, mais aussi pour ceux qui voudraient mesurer combien cet effet miroir est en train de changer la vision occidentale du musée.

\section{AUTEURS}

\section{ALICE BOMBARDIER}

Chargé de cours à l'INALCO 